\title{
Prefabrike Yapıların Tasarım, Üretim, Depolama, Nakliye ve Yapım Süreçlerini Etkileyen Faktörler
}

\author{
İlhami AY ${ }^{1}$ \\ Gülden GÜMÜŞBURUN AYALP²
}

\section{ÖZ}

Prefabrikasyon, inşaat sektöründe sanayileşmenin başlangıcı olarak kabul edilir ve bu süreçleri makineleşme, otomatik kontrol ve üretim takip etmektedir. Prefabrik inşaat teknolojisi, binaların daha kolay ve hızlı, daha düşük maliyet, daha başarılı kalite kontrol ve daha az malzeme israfı ile yapılmasına da olanak tanımaktadır. Prefabrike sistemlerin birçok avantajı olmasına rağmen, Türkiye'de prefabrike yapı sistemlerin kullanımı çok düşük seviyelerdedir. $\mathrm{Bu}$ araştırmanın amacı, Türkiye'de prefabrik yapı sistemlerinin yaygın kullanımını etkileyen faktörleri tespit etmektir. Bu amaçla mimarlardan, prefabrik eleman üretimi yapan firma çalışanlarından ve yüklenicilerden anket yöntemiyle veri toplanmış; toplanan verilere SPSS 22 programı aracılığı ile güvenilirlik analizi ve açıklayıcı faktör analizi uygulanmıştır. Çalışmanın sonucunda Türkiye'de prefabrike yapım sistemlerinin yaygın kullanımını etkileyen dokuz ana faktör belirlenmiştir.

Anahtar Kelimeler: Prefabrikasyon, proje ve yapım yönetimi, Türk inşaat sektörü.

\section{ABSTRACT \\ Factors Affecting the Design, Manufacturing, Storage, Transportation, and Construction Processes of Prefabricated Buildings}

Prefabrication is considered as the beginning of industrialization in the construction sector and these processes are followed by mechanization, automatic control and production. Prefabricated construction technology allows the building to be made easier and faster, with lower cost, more successful quality control and less material waste. Although there are many advantages of prefabricated systems, the use of prefabricated building systems in Turkey is at very low levels. The main objective of this research is to identify factors affecting the prevalent use of prefabricated building systems in Turkey. In order to reach the aim using

\footnotetext{
Not: Bu yazı

- Yayın Kurulu'na 15 Kasım 2019 günü ulaşmıştır. 17 Ağustos 2020 günü yayımlanmak üzere kabul edilmiştir.

- 31 Temmuz 2021 gününe kadar tartışmaya açıktır.

- https://doi.org/10.18400/tekderg.647272

1 Hakkari Üniversitesi, Çölemerik Meslek Yüksek Okulu, Mimarlık ve Şehir Planlama Bölümü, Hakkari ilhamiay@hakkari.edu.tr - https://orcid.org/0000-0002-3506-3234

2 Hasan Kalyoncu Üniversitesi, Mimarlık Bölümü, Gaziantep - gulden.ayalp@hku.edu.tr https://orcid.org/0000-0002-7989-5569
} 
questionnaire data obtained from architects, employees of prefabricated element manufacturers and contractors. Reliability analyze and exploratory factor analyze were conducted using SPSS 22.0 software on obtained data. As a result of the study nine main factors that affect the use of prefabricated construction systems in Turkey was found.

Keywords: Prefabrication, construction management, Turkish construction industry.

\section{GİRIŞ}

Prefabrikasyon üretimde amaç "önceden hazırlanmış olan prefabrike elemanlar ile hızlı bir şekilde birleşim yaparak, inşaatı kolaylaştırmak, ekonomik kazanç sağlamak, zamandan kazanmak ve gereken konforu sağlamaktır" [1]. Diğer bir ifade ile şantiyeye en az sayıda iş bırakacak şekilde fabrikadaki işçilik kalitesini ve kapasitesini kontrol ederek çalışma şartlarında belirli bir kalite düzeyini sağlamak ve standartlaşmayı artırmak prefabrikasyonun genel amacidir.

Bir bina projesinin yapımında prefabrik betonarme yapı elemanlarının kullanılması, proje toplam maliyetinin azaltılması, projenin hızlı bir şekilde tamamlanması, yapı elemanlarında istenilen kalite ve mukavemetin sağlanması, malzeme israfının azaltılması, modülarizasyon ve standardizasyon olanaklarının artırılması ve şantiyede meydana gelebilecek iş kazası sayısını önemli ölçüde azaltılabilmesi gibi birçok yarar sağlamaktadır [2,3]. Avrupa ve Asya ülkelerinde prefabrik betonarme yapı sistemleri yarım asrı aşkın bir süredir yaygın bir şekilde başarı ile kullanılmakta iken, Türkiye'de söz konusu yapım sistemlerinin kullanımı yaygınlaşmakla beraber hala düşük oranlarda tercih edilmektedir [4-7]. Bu durumun nedeninin prefabrike yapıların yaşam döngüsü süreçlerinin her aşamasında karşılaşılan sorunlar olduğu düşünülmektedir. Bu nedenle bu çalışmada, Türk inşaat sektöründe prefabrike yapıların yapım üretim sürecini etkileyen faktörlerin belirlenmesi amaçlanmıştır.

Prefabrike yapım sistemlerinin sağladığı avantajlar pek çok araştırmacının dikkatini çekmiştir ve ilgili literatür incelendiğinde son yıllarda konuyla ilgili pek çok çalışmanın yapıldığı görülmektedir [8-16]. Söz konusu çalışmalar incelendiğinde araştırmaların prefabrike sistemlerin yapısal analizleri, fayda-maliyet analizleri veya temiz üretim konuları üzerine yoğunlaştığı görülmektedir. Daha önceki yıllarda yapılmış çalışmalar incelendiğinde ise prefabrike yapım sistemlerinin, tasarım sürecinden başlayarak uygulama sürecine kadar tüm aşamaları etkileyebilecek kriterlerin bir arada ele alınarak prefabrike yapım sistemlerinin kullanımını etkileyen faktörlerin belirlendiği bir çalışmaya rastlanmamıştır. Yapılmış önceki çalışmalarda iki farklı yöntem izlenmiştir. Bir grup çalışmada prefabrike yapım sistemlerine yönelik süreçleri etkileyen kriterler ele alınmış, alan çalışması yapılmış ve elde edilen veriler yüzde, frekans ve ortalama değerlerine göre yorumlanmıştır [2, 5-7, 19, 21, 26]. Diğer grup çalışmalarda ise prefabrike yapım sistemlerinin sadece bir sürecine odaklanarak süreci olumsuz etkileyen kriterler belirlenmiş ve söz konusu kriterlere faktör analizi uygulanmıştır [4]. Yapılan bu çalışmada prefabrike yapıların tasarım, yapı elemanlarının üretim, depolama, nakliye ve uygulama süreçlerini etkileyen kriterler bir arada ele alınarak faktör analizi uygulanmıştır. Prefabrike yapıların üretimindeki tüm süreçleri etkileyen ana faktörlerin belirlenmesi çalışmayı diğer araştırmalardan farklılaştırmaktadır.

Birçok yapı üretim sisteminde olduğu gibi prefabrike yapıların üretim sürecinde de pek çok paydaş bir arada çalışmaktadır. Yapıların tasarım sürecinde mimarlar, prefabrike yapı 
elemanlarının üretim sürecinde ilgili yapı elemanının üretimine katkı koyan üretici firmalar ve montaj ve uygulamayı gerçekleştiren yükleniciler prefabrike yapıların tasarım, üretim ve uygulama süreçlerinde başrol üstlenmektedirler. Bu nedenle, çalışmanın ana amacına ulaşılmasında her üç gruptaki katılımcılardan görüş alınmıştır. Prefabrike bir yapının tasarım aşamasından başlayıp yapım aşamasının sonuna kadar olan tüm süreçlerde karşılaşılabilecek değişkenlerin araştırmaya dahil edilmesi çalışmanın değerini oluşturmaktadır.

\section{PREFABRIKE YAPILARIN TASARIM, ÜRETIM, DEPOLAMA, NAKLIYE VE YAPIM SÜREÇLERINI ETKILEYEN KRITERLERIN BELIRLENMESI}

Prefabrike yapıların tasarımı, bu yapılarda kullanılacak yapı elemanlarının üretimi, depolama ile nakliye süreçleri ile bu yapıların yapım süreçlerini etkileyen faktörlerin belirlenebilmesi için faktörlere kaynaklık edecek nedenlerin/kriterlerin belirlenmesi önem arz etmektedir. Çalışma kapsamında yapılan literatür taraması sonucunda adı geçen süreçleri etkileyen 46 kriter elde edilmiştir. Çalışma kapsamında ele alınan kriterler ve ilgili literatür Çizelge 1'de görülmektedir.

Çizelge 1 - Prefabrike yapım sistemlerinin yaygın kullanımına etkileyen kriterler

\begin{tabular}{|c|c|c|c|}
\hline SÜREÇLER & $\begin{array}{c}\text { Madde } \\
\text { Kodu }\end{array}$ & Kriterler & Kaynak \\
\hline \multirow{10}{*}{ 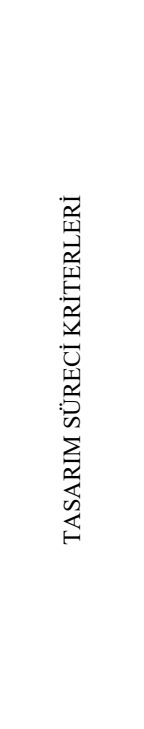 } & $\mathrm{T} 1$ & $\begin{array}{l}\text { Prefabrike betonarme yapı elemanlarının çeşitliliğinin az olması tasarımı } \\
\text { kısıtlamaktadır. }\end{array}$ & {$[4],[6],[17]$} \\
\hline & $\mathrm{T} 2$ & $\begin{array}{l}\text { Prefabrike betonarme yapı elemanlarının dinamik yükler altındaki performansı } \\
\text { tasarımları olumsuz etkilemektedir. }\end{array}$ & {$[6],[17],[18],[19]$} \\
\hline & $T 3$ & $\begin{array}{l}\text { Prefabrike betonarme yapı elemanları çeşitliliğinin az olması tasarımlardaki } \\
\text { yaratıcılığı olumsuz etkilemektedir. }\end{array}$ & {$[4],[5],[6],[8]$} \\
\hline & $\mathrm{T} 4$ & $\begin{array}{l}\text { Prefabrike betonarme yapı elemanları konusunda yeterli bilgi düzeyine sahip } \\
\text { olunmaması tasarım sürecini olumsuz etkilemektedir. }\end{array}$ & {$[4],[6],[17]$} \\
\hline & T5 & $\begin{array}{l}\text { Tasarım sürecinde paydaşlar arası(inşaat mühendisi, müteahhit, üretici firma } \\
\text { vs.) bilgi akışının yetersiz olması tasarım sürecini olumsuz etkilemektedir. }\end{array}$ & {$[5],[6],[12],[20]$} \\
\hline & T6 & $\begin{array}{l}\text { Tasarımcıların, üretici firmalara prefabrike elemanın tasarım aşamasında } \\
\text { danışmanlık yapmaması üretim sürecini olumsuz etkilemektedir. }\end{array}$ & {$[6],[20]$} \\
\hline & $\mathrm{T} 7$ & $\begin{array}{l}\text { Paydaşlar arası(inşaat mühendisi, müteahhit, üretici firma vs.) periyodik } \\
\text { toplantılar yapılmaması tasarım sürecini olumsuz etkilemektedir. }\end{array}$ & {$[6],[17]$} \\
\hline & $\mathrm{T} 8$ & $\begin{array}{l}\text { Prefabrike yapı sistemlerinin esnek tasarımlara imkan vermemesi tasarımları } \\
\text { kısıtlamaktadır. }\end{array}$ & {$[4],[17]$} \\
\hline & $T 9$ & $\begin{array}{l}\text { Prefabrik yapı elemanı boyutları, ekonomik ă̆ırlı̆ } \breve{l} \text { ve tekrar eden panel } \\
\text { sayısının dikkate alınmaması tasarımı olumsuz etkilemektedir. }\end{array}$ & {$[4],[5]$} \\
\hline & $\mathrm{T} 10$ & $\begin{array}{l}\text { Prefabrike yapı elemanlarının kullanıldığı bina projelerinin tasarımında } \\
\text { uzmanlaşmış mühendis/mimar sayısının az olması tasarım sürecini olumsuz } \\
\text { etkilemektedir. }\end{array}$ & {$[5],[19]$} \\
\hline \multirow{4}{*}{ 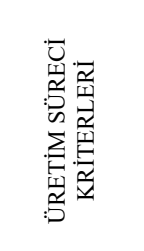 } & Ü1 & $\begin{array}{l}\text { Üretim sürecinde gerekli olan nitelikli iş gücü temininin sağlanmaması süreci } \\
\text { olumsuz etkilemektedir. }\end{array}$ & {$[5],[6],[19]$} \\
\hline & Ü2 & $\begin{array}{l}\text { Üretim sürecinde kalite-kontrol sisteminin kurulamaması süreci olumsuz } \\
\text { etkilemektedir. }\end{array}$ & {$[5],[21],[22]$} \\
\hline & Ü3 & $\begin{array}{l}\text { Prefabrik yapı elemanının tasarım sürecinde yapılan hatalar, ilgili prefabrik } \\
\text { elemanın hatalı/eksik üretilmesi üretilmesine neden olmaktadır. }\end{array}$ & {$[6]$} \\
\hline & Ü4 & Üretici firmalar teknik çizime uygun üretim yapmamaktadır. & {$[21],[22]$} \\
\hline
\end{tabular}




\section{Çizelge 1 - Prefabrike yapım sistemlerinin yaygın kullanımına etkileyen kriterler (devam)}

\begin{tabular}{|c|c|c|c|}
\hline SÜREÇLER & $\begin{array}{c}\text { Madde } \\
\text { Kodu }\end{array}$ & Kriterler & Kaynak \\
\hline \multirow{8}{*}{ 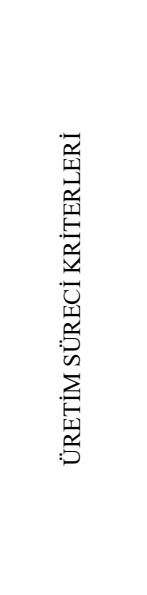 } & Ü5 & $\begin{array}{l}\text { Üretici firmalarda teknik çizim okuma ve uygulama yapmayan bilmeyen } \\
\text { elemanların sayıca çok olması ve/veya istihdam edilmesi üretim sürecini } \\
\text { olumsuz etkilemektedir. }\end{array}$ & {$[4],[5],[19]$} \\
\hline & Ü6 & $\begin{array}{l}\text { Prefabrik yapı elemanın üretim sürecinde kullanılan betonun vibrasyonu } \\
\text { yeterli düzeyde yapılmamaktadır. }\end{array}$ & [23] \\
\hline & Ü7 & $\begin{array}{l}\text { Prefabrik yapı elemanlarının hatalı üretilmesi işin teslim sürecini } \\
\text { geciktirmektedir. }\end{array}$ & [23] \\
\hline & Ü8 & $\begin{array}{l}\text { Montaj işleminin iş programına uygun olarak yapılamaması süreci olumsuz } \\
\text { etkilemektedir. }\end{array}$ & {$[5],[23]$} \\
\hline & Ü9 & $\begin{array}{l}\text { Prefabrik yapı elemanın üretim sürecinde korozyona uğramış donatı veya ön } \\
\text { gerilim teli kullanılmaktadır }\end{array}$ & [23] \\
\hline & $\ddot{U} 10$ & $\begin{array}{l}\text { Prefabrik yapı elemanın üretim sürecinde nitelik ve boyut olarak uygun } \\
\text { agrega kullanılmaktadır. }\end{array}$ & [23] \\
\hline & U11 & $\begin{array}{l}\text { Kalıplardaki deformasyon kaynaklı hatalar üretim sürecini olumsuz } \\
\text { etkilemektedir. }\end{array}$ & [23] \\
\hline & U12 & $\begin{array}{l}\text { Prefabrik yapı elemanın üretim sürecinde teknik şartnamelere uygun üretim } \\
\text { yapılmamaktadır }\end{array}$ & {$[5]$} \\
\hline \multirow{6}{*}{ 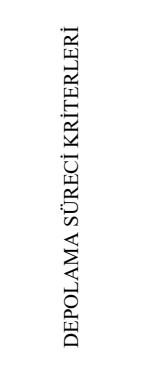 } & D1 & $\begin{array}{l}\text { Prefabrik yapı elemanlarının yanlış biçimde depolanması yapı elemanlarının fiziksel } \\
\text { hasarlarına sebep olmaktadır. }\end{array}$ & {$[24],[25],[26]$} \\
\hline & D2 & $\begin{array}{l}\text { Prefabrik yapı elemanlarının depolanma sürecinde korunamaması elemanlarda, boyutsal ve } \\
\text { işlevsel hasarlar oluşuna neden olmaktadır. }\end{array}$ & {$[24],[25]$} \\
\hline & D3 & $\begin{array}{l}\text { Depo alanlarının prefabrik yapı elemanlarının özelliklerine ve boyutlarına uygun olmaması, } \\
\text { elemanlarda hasara sebep olmaktadır }\end{array}$ & {$[24],[25],[26]$} \\
\hline & D4 & $\begin{array}{l}\text { Depolama sürecinin iş programlarına uygun olarak planlanmaması eleman hasarlarına ve } \\
\text { ekonomik kayıplara neden olmaktadır. }\end{array}$ & {$[24],[25],[26]$} \\
\hline & D5 & $\begin{array}{l}\text { Depolama alanı ve stok kontrolünün deneyimli olmayan kişilerin sorumluluğunda ve } \\
\text { denetiminde olması ekonomik, organizasyonel ve zamanla ilgili sorunlara yol açmaktadır. }\end{array}$ & {$[5],[6],[26]$} \\
\hline & D6 & $\begin{array}{l}\text { Sipariş için uygun zaman belirlenmemesi optimum süreyi olumsuz etkileyerek gecikmelere } \\
\text { neden olmaktadır. }\end{array}$ & {$[20],[25],[26]$} \\
\hline \multirow{12}{*}{ 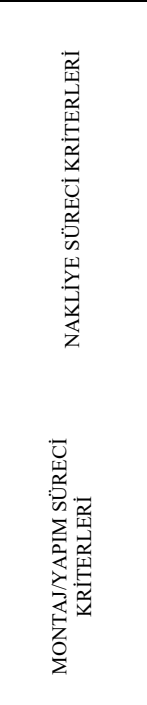 } & N1 & $\begin{array}{l}\text { Üretilen prefabrik yapı elemanlarının nakliye sürecinde karayollarının getirmiş olduğu yasal } \\
\text { sınırlılıklar prefabrik yapım sisteminin kullanımını olumsuz etkilemektedir. }\end{array}$ & $\begin{array}{l}{[4],[6],[24],[25],} \\
{[26]}\end{array}$ \\
\hline & $\mathrm{N} 2$ & $\begin{array}{l}\text { Üretilen yapı elemanlarının yükleme yapılan tesis ile şantiye arasındaki taşıma mesafesinin } \\
\text { fazla olması sorunlara sebep olmaktadır. }\end{array}$ & $\begin{array}{l}{[4],[5],[6],[19],} \\
{[24],[25],[26]}\end{array}$ \\
\hline & N3 & $\begin{array}{l}\text { Taşıma işlemi yapılacak yolların fiziksel durumu prefabrik yapı elemanın zarar görmesine } \\
\text { sebep olmaktadır. }\end{array}$ & {$[6],[26]$} \\
\hline & N4 & $\begin{array}{l}\text { Nakliye sırasında yeterli özenin gösterilmemesi prefabrik elemanlara fiziksel zarar } \\
\text { vermektedir. }\end{array}$ & {$[6],[23],[26]$} \\
\hline & N5 & Taşıma aracının doğru seçilmemesi prefabrik yapı elemanlarına hasar vermektedir. & {$[6],[26]$} \\
\hline & N6 & Taşıma yönteminin doğru seçilmemesi prefabrik yapı elemanlarına hasar vermektedir. & {$[6],[19],[26]$} \\
\hline & N7 & $\begin{array}{l}\text { Nakliye planının iş programına uygun yapılmaması ya da hiçbir plana uygun yapılmaması } \\
\text { yapım sürecini olumsuz etkilemektedir. }\end{array}$ & {$[6],[25],[26]$} \\
\hline & M1 & $\begin{array}{l}\text { Prefabrik yapı elemanlarında kolon-kiriş birleşimiyle ilgili sorunlar montaj sürecini olumsuz } \\
\text { etkilemektedir. }\end{array}$ & {$[4],[19],[27]$} \\
\hline & M2 & $\begin{array}{l}\text { Prefabrik yapı elemanlarında kolon-duvar birleşimiyle ilgili sorunlar montaj sürecini } \\
\text { olumsuz etkilemektedir. }\end{array}$ & {$[4],[19],[27]$} \\
\hline & M3 & $\begin{array}{l}\text { Prefabrik yapı elemanlarında kolon-kolon birleşimiyle ilgili sorunlar montaj sürecini } \\
\text { olumsuz etkilemektedir. }\end{array}$ & {$[4],[19],[27]$} \\
\hline & M4 & $\begin{array}{l}\text { Prefabrik yapı elemanlarında temel-kolon birleşimiyle ilgili sorunlar montaj sürecini olumsuz } \\
\text { etkilemektedir. }\end{array}$ & {$[4],[19],[27]$} \\
\hline & M5 & $\begin{array}{l}\text { Prefabrik yapı elemanlarında kiriş-kiriş birleşimiyle ilgili sorunlar montaj sürecini olumsuz } \\
\text { etkilemektedir. }\end{array}$ & {$[4],[19],[27]$} \\
\hline
\end{tabular}


Çizelge 1 - Prefabrike yapım sistemlerinin yaygın kullanımına etkileyen kriterler (devam)

\begin{tabular}{|c|c|c|c|}
\hline SÜREÇLER & $\begin{array}{l}\text { Madde } \\
\text { Kodu }\end{array}$ & Kriterler & Kaynak \\
\hline \multirow{6}{*}{ 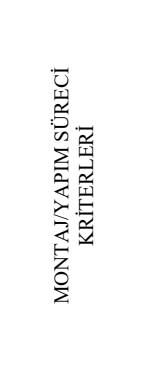 } & M6 & $\begin{array}{l}\text { Yapılan montajlarda denetiminde görev alacak prefabrike yapım sisteminde } \\
\text { uzmanlaşmış/bilgi sahibi mimar/mühendis sayısının az olması yapım sürecini olumsuz } \\
\text { etkilemektedir. }\end{array}$ & $\begin{array}{l}{[5],[6],[19],[21]} \\
{[22],[27]}\end{array}$ \\
\hline & M7 & $\begin{array}{l}\text { Yapım sürecinde yer alacak nitelikli iş gücünün temin edilememesi süreci olumsuz } \\
\text { etkilemektedir. }\end{array}$ & {$[4],[5],[6],[27]$} \\
\hline & M8 & Montaj işleminin iş programına uygun olarak yapıllamaması süreci olumsuz etkilemektedir. & [28] \\
\hline & M9 & $\begin{array}{l}\text { Şantiye planı yapılırken vinçlerin hareket düzeninin dikkate alınmaması yapım sürecini } \\
\text { olumsuz etkilemektedir }\end{array}$ & {$[4],[5],[24],[27]$} \\
\hline & M10 & $\begin{array}{l}\text { Yapılan montajların kalite-kontrol planı dâhilinde denetlenmemesi yapım sürecini olumsuz } \\
\text { etkilemektedir }\end{array}$ & $\begin{array}{l}{[5],[21],[22],[27],} \\
{[29],[30]}\end{array}$ \\
\hline & M11 & $\begin{array}{l}\text { Yapılan montajların periyodik olarak takip edilmemesi yapım sürecini olumsuz } \\
\text { etkilemektedir. }\end{array}$ & {$[21],[22],[27],[31]$} \\
\hline
\end{tabular}

T: Tasarım Ü: Üretim N: Nakliye D: Depolama M: Montaj

\section{ARAŞTIRMANIN YÖNTEMI}

Çalışmanın amacı doğrultusunda, çalışma prefabrike yapıların tasarım, yapı elemanlarının üretimi, depolama, nakliye ve montaj aşamalarını olumsuz etkileyebilecek değişkenleri belirlemek için kapsamlı bir literatür taraması ile başlamıştır. Literatür taraması sonucunda tasarım sürecine yönelik 10 [4-6,8,12,17-20], üretim süreci için 12 [4-6, 19, 21-23], depolama süreci için $6[5,6,20,24-26]$, nakliye süreci için $7[4-6,19,23-26]$ ve son olarak montaj/uygulama süreci için 11 [4-6, 19, 19, 21, 22, 27-31] olmak üzere toplam 46 kriter belirlenmiştir. Belirlenen kriterler 5'li Likert ölçeği ile anket sorusu olarak düzenlenmiştir. Likert ölçeği ile hazırlanan anket sorularının içsel tutarlıklarının ölçülmesi gerekmektedir [32]. Bu nedenle, Likert ölçeği ile hazırlanan 46 maddeye/kritere güvenilirlik analizi uygulanmıştır. Çalışmanın amacına ulaşabilmek için aynı yapıyı ölçen çok sayıda değişkenden, az sayıda ve tanımlanabilir nitelikte anlamlı değişkenler elde etmeye yönelik çok değişkenli bir istatistik olan açıklayıcı faktör analizi [33] kullanılmıştır.

Türk inşaat sektöründe prefabrike yapıların tasarım sürecinde bulunan mimarlar, prefabrike yapı elemanlarının üretim sürecinde yer alan üretici firma çalışanları ve prefabrike yapıların uygulama sürecinden sorumlu yükleniciler bu çalışmanın hedef popülasyonunu oluşturmaktadır. Belirlenen popülasyon içerisinde her bir ana kitleden basit rastgele örneklem seçimi yöntemi ile çalışmanın örneklemi belirlenmiştir. Hazırlanan anket formları çevrimiçi hale getirilerek Türkiye Prefabrik Birliğine üye olan 35 üretici firma yetkilisine eposta yoluyla ulaştırılmış ve firma çalışanlarına da anket formunun ulaştırılması için destek alınmıştır. Anketlerin ülke genelinde mimarlara ve yüklenicilere ulaştırılmasında profesyonel organizasyonlardan destek alınmıştır. Ayrıca çevrimiçi hale getirilen anketler, Türkiye genelinde meslek odalarına ve birliklere bağlı üyelere de internet ortamında ulaştırılarak mimarların ve yüklenicilerin katılımı sağlanmıştır. Anketler katılımcılara Kasım 2018 -Ocak 2019 tarihleri arasında ulaştırılmıştır. Türk inşaat sektöründe aktif şekilde faaliyet gösteren prefabrike yapıların tasarımını yapan 51 mimar, üretici firma çalışanı 34 teknik eleman ve prefabrike yapıların uygulama sürecinde görev alan 45 yüklenici çalışanın örneklemini oluşturmaktadır. 


\section{BULGULAR VE TARTIŞMA}

Örneklem grubundan anket yöntemiyle toplanan veriler istatistiksel yöntemlerle analiz edilmiştir. Bu kapsamda madde güvenilirlik analizi ve açıklayıcı faktör analizi kullanılmıştır. Çalışma kapsamında ilk olarak algıya dayalı verilere güvenilirlik analizi yapılmıştır. Analiz sonucunda Cronbach Alfa değerinin $\alpha=0,960$ olarak oluştuğu görülmektedir. Cronbach Alfa katsayısı $(\alpha) 0$ ile 1 arasında değer almaktadır. Yaygın kabul edilen yaklaşıma göre $\alpha$ katsayısı 0,5 'den küçük ise ölçeğin güvenilirliği kabul edilemez; $0,5 \leq \alpha<0,6$ ise zayıf; $0.6 \leq$ $\alpha<0,7$ kabul edilebilir; $0,7 \leq \alpha<0,9$ iyi; $\alpha \geq 0,90$ mükemmel güvenilirlik göstermektedir [34]. $\mathrm{Bu}$ değere göre anketin yüksek derecede güvenilir olduğu söylenebilir. Anketin içsel tutarlığı sağlandıktan sonra açıklayıcı faktör analizi uygulanmıştır. Faktör analizi sonucunda faktör yükü 0,4 'ün altında olan üç soru araştırma dışı bırakılmış ve 43 sorudan elde edilen verilerle analizler tekrarlanmıştır. Faktör analizi sonucu faktörler altında toplanan maddelerin faktör yükleri ve bu maddelerin içeriğine göre adlandırılmış faktörler Çizelge 2'de görülmektedir.

Çizelge 2 - Açıklayıcı faktör analizi

\begin{tabular}{|c|c|c|c|c|}
\hline Faktörler & $\begin{array}{l}\text { Madde } \\
\text { Kodları }\end{array}$ & $\begin{array}{l}\text { Faktör } \\
\text { Yükleri }\end{array}$ & $\begin{array}{c}\text { Faktör } \\
\text { Açıklayıcıları }\end{array}$ & $\begin{array}{c}\text { Faktör } \\
\text { Güvenilirlikleri }\end{array}$ \\
\hline \multirow{10}{*}{$\begin{array}{l}\text { FAKTÖR 1- Nakliye ve Depolama Süreçleri ile } \\
\text { İlgili Bilgi Eksikliği }\end{array}$} & N5 & 0,809 & \multirow{10}{*}{16,645} & \multirow{10}{*}{0,944} \\
\hline & N7 & 0,759 & & \\
\hline & N6 & 0,745 & & \\
\hline & D1 & 0,736 & & \\
\hline & D5 & 0,720 & & \\
\hline & D4 & 0,698 & & \\
\hline & D6 & 0,693 & & \\
\hline & $\mathrm{N} 4$ & 0,628 & & \\
\hline & D3 & 0,586 & & \\
\hline & D2 & 0,581 & & \\
\hline \multirow{6}{*}{$\begin{array}{l}\text { FAKTÖR 2- Prefabrike Yapt Elemanlart } \\
\text { Arasindaki Uyumsuzluklar }\end{array}$} & M2 & 0,805 & \multirow{6}{*}{11,844} & \multirow{6}{*}{0,908} \\
\hline & M1 & 0,799 & & \\
\hline & M3 & 0,791 & & \\
\hline & M5 & 0,787 & & \\
\hline & M4 & 0,617 & & \\
\hline & Ü3 & 0,512 & & \\
\hline \multirow{6}{*}{$\begin{array}{l}\text { FAKTÖR 3- Uygulama Sürecinde Planlama, } \\
\text { Organizasyon ve Denetim Eksikliği }\end{array}$} & M11 & 0,770 & \multirow{6}{*}{10,232} & \multirow{6}{*}{0,881} \\
\hline & M6 & 0,713 & & \\
\hline & M10 & 0,703 & & \\
\hline & M8 & 0,693 & & \\
\hline & M9 & 0,660 & & \\
\hline & $\mathrm{T} 8$ & 0,565 & & \\
\hline
\end{tabular}


Çizelge 2 - Açıklayıcı faktör analizi (devam)

\begin{tabular}{|c|c|c|c|c|c|}
\hline \multicolumn{2}{|l|}{ Faktörler } & $\begin{array}{l}\text { Madde } \\
\text { Kodları }\end{array}$ & $\begin{array}{l}\text { Faktör } \\
\text { Yükleri }\end{array}$ & $\begin{array}{c}\text { Faktör } \\
\text { Açıklayıcıları }\end{array}$ & $\begin{array}{c}\text { Faktör } \\
\text { Güvenilirlikleri }\end{array}$ \\
\hline \multirow{6}{*}{\multicolumn{2}{|c|}{$\begin{array}{l}\text { FAKTÖR 4- Tasarım Sürecinde Paydaşlar Arast } \\
\text { Koordinasyon Eksikliği }\end{array}$}} & $\ddot{\mathrm{U}} 4$ & 0,774 & \multirow{6}{*}{10,151} & \multirow{6}{*}{0,866} \\
\hline & & $\mathrm{T} 6$ & 0,645 & & \\
\hline & & $\mathrm{N} 1$ & 0,626 & & \\
\hline & & Ü6 & 0,589 & & \\
\hline & & $\mathrm{T} 7$ & 0,534 & & \\
\hline & & $\mathrm{T} 5$ & 0,455 & & \\
\hline \multirow{4}{*}{\multicolumn{2}{|c|}{$\begin{array}{l}\text { FAKTÖR 5- Konu ile ilgili Uzman Mimar ve } \\
\text { Mühendis Saylstntn Yetersizliği }\end{array}$}} & $\mathrm{T} 4$ & 0,773 & \multirow{4}{*}{7,435} & \multirow{4}{*}{0,787} \\
\hline & & Ü2 & 0,752 & & \\
\hline & & Ü1 & 0,653 & & \\
\hline & & $\mathrm{T} 10$ & 0,619 & & \\
\hline \multirow{3}{*}{\multicolumn{2}{|c|}{$\begin{array}{l}\text { FAKTöR 6- Kisttl çeşit türü, dinamik yükler } \\
\text { altındaki performans ve teknik şartnameye } \\
\text { uygun üretim yapılmamast }\end{array}$}} & $\mathrm{T} 1$ & 0,734 & \multirow{3}{*}{6,613} & \multirow{3}{*}{0,779} \\
\hline & & $\mathrm{T} 2$ & 0,622 & & \\
\hline & & Ü12 & 0,586 & & \\
\hline \multirow{4}{*}{\multicolumn{2}{|c|}{ FAKTÖR 7- Uygunsuz malzeme kullanımı }} & Ü11 & 0,740 & \multirow{4}{*}{5,806} & \multirow{4}{*}{0,815} \\
\hline & & Ü9 & 0,655 & & \\
\hline & & Ü7 & 0,627 & & \\
\hline & & Ü8 & 0,506 & & \\
\hline \multirow{2}{*}{\multicolumn{2}{|c|}{$\begin{array}{l}\text { FAKTÖR 8- Yapt Elemanlarının Üretim ve } \\
\text { Montaj Süreçlerinde Teknik, Teorik ve } \\
\text { Uygulama Bilgisi Eksikliği }\end{array}$}} & M7 & 0,646 & \multirow[b]{2}{*}{4,483} & \multirow[b]{2}{*}{0,705} \\
\hline & & Ü5 & 0,602 & & \\
\hline \multirow{2}{*}{\multicolumn{2}{|c|}{$\begin{array}{l}\text { FAKTÖR 9- Nakliye Süreci ile İlgili Yasal } \\
\text { KIsttlamalar }\end{array}$}} & $\mathrm{N} 2$ & 0,838 & \multirow{2}{*}{4,173} & \multirow{2}{*}{0,725} \\
\hline & & N3 & 0,468 & & \\
\hline \multicolumn{3}{|c|}{ Açıklanan Toplam Varyans: } & 77,382 & & \\
\hline \multicolumn{3}{|c|}{ Kaiser-Meyer-Olkin (KMO) Ölçek Geçerliliği: } & 0,650 & & \\
\hline \multirow{3}{*}{$\begin{array}{l}\text { Bartlett } \\
\text { Küresellik } \\
\text { Değerleri }\end{array}$} & Ki-Kare & & & & 6693,500 \\
\hline & Sd: & & & & 903 \\
\hline & p: & & & & 0,000 \\
\hline
\end{tabular}

T: Tasarım Ü: Üretim N: Nakliye D: Depolama M: Montaj

Faktör analiz sonucunda, örneklem büyüklüğünün faktör analizi için uygunluğunu test eden KMO değeri 0,650 ve Barlett Küresellik değeri $p=0.000$ olarak hesaplanmıştır. Bu değerlere göre örneklem büyüklüğünün faktör analizi için yeterli olduğu sonucuna ulaşılmıştır.

Açıklayıcı faktör analizinde Özdeğer ve Varimax döndürme yöntemi kullanılarak, Özdeğeri 1'den büyük 9 adet faktör elde edilmiştir. Türk inşaat sektöründe prefabrike yapım sistemlerinin yaygın kullanılmasına neden olan 43 madde 9 faktör altında toplanmış ve bu 9 faktör toplam varyansın \%77,382'ini açıkladığı belirlenmiştir. Faktörlerin içsel tutarlılığının hesaplanmasında, Cronbach Alpha değeri kullanılmıştır. Faktörlerin Cronbach Alpha 
değerleri (faktör güvenilirlikleri) 0,70’in üzerinde olduğundan güvenilirliğin yüksek olduğu belirlenmiştir.

Birinci faktör, toplam varansın \%16,645'ini açıklamış ve altında 10 madde toplamıştır. Maddelerin içeriği incelenerek birinci faktör "Nakliye ve depolama süreçleri ile ilgili bilgi eksikliği” olarak isimlendirilmiştir. Diğer faktörler ise altında toplanan maddelerin içeriği incelenerek sırasıyla "Prefabrike yapı elemanları arasındaki uyumsuzluklar"; "Uygulama sürecinde planlama, organizasyon ve denetim eksikliği"; "Tasarım sürecinde paydaşlar arası koordinasyon eksikliği”; "Konu ile ilgili uzman mimar ve mühendis sayısının yetersizliği”; "Kısıtlı çeşit türü, dinamik yükler altındaki performans ve teknik şartnameye uygun üretim yapılmaması";" Uygunsuz malzeme kullanımı"; "Yap1 elemanlarının üretim ve montaj süreçlerinde teknik, teorik ve uygulama bilgisi eksikliği"; "Nakliye süreci ile ilgili yasal kısıtlamalar" olarak adlandırılmıştır.

Türk inşaat sektöründe prefabrike yapım sistemlerinin yaygın kullanılmasını etkileyen dokuz ana faktörün ilki "Nakliye ve depolama süreçleri ile ilgili bilgi eksikliği" olarak belirlenmiştir. Çalışmanın bu bulgusunun literatürde yapılmış çalışmalarla [5, 6, 19, 20, 2326] tutarlılık gösterdiği görülmektedir.

"Prefabrike yapı elemanları arasındaki uyumsuzluklar" ikinci faktör olarak belirlenmiştir. Jaillon ve Poon [2]'un prefabrike yapım sistemlerini avantaj ve dezavantajlarını belirledikleri çalışmada prefabrike yapı elemanları arasındaki uyumsuzlukların sistemin önemli bir kısıtlayıcısı olması dikkat çekmektedir. Polat [19]'ın çalışma sonucuna göre ise prefabrike yapı elemanları arasındaki uyumsuzluklar adı geçen sistemin yaygın kullanılmaması için önemli bir kriter olarak belirlenmiştir.

Çalışma bulgusunda belirlenen "Uygulama sürecinde planlama, organizasyon ve denetim eksikliği” faktörü konuyla ilgili yapılmış çalışmalarda ayrıntılı olarak ele alınmamıştır. Oysaki yönetimin fonksiyonlarından olan planlama, organizasyon ve denetim yapı üretim sürecinin etkin bir şekilde gerçekleştirilebilmesi için önemli gerekliliklerdir. Mevcut çalışmanın bu sonucunun literatürdeki boşluğu dolduracağı düşünülmektedir.

“Tasarım sürecinde paydaşlar arası koordinasyon eksikliğii” konuyla ilgili yapılmış önceki çalışmalarda da ele alınan önemli bir faktördür [5-7,17, 20-23]. Çalışmanın bu bulgusunun literatürdeki çalışma sonuçlarıyla uyum gösterdiği söylenebilir.

"Konu ile ilgili uzman mimar ve mühendis sayısının yetersizliği" ve "Yapı elemanlarının üretim ve montaj süreçlerinde teknik, teorik ve uygulama bilgisi eksikliği” yapılmış çalışmalarda da sıklıkla ele alınan kriterlerdendir [4-7]. Bu bulgular ile hem ülkemizde hem de farklı ülkelerde (Hong Kong, Singapur, Malezya) prefabrike yapım sistemlerinin tasarım ve uygulanması aşamalarında görev alan mimar ile mühendislerin ve prefabrike yapı elemanlarının üretim sürecinde bulunan ara teknik elemanların konuyla ilgili yeterli seviyede bilgi sahibi olmadığ sonucuna ulaşılmıştır.

\section{SONUÇLAR}

Türk inşaat sektöründe prefabrike yapıların yaygın kullanılmasını engelleyen faktörlerin belirlenmesinin amaçlandığ 1 bu çalışmada prefabrike yapıların tasarım, yapı elemanlarının üretim, depolama, nakliye ve montaj süreçlerinde görev alan mimar, yüklenici ve üretici 
firma çalışanlarından anket yöntemiyle veri toplanmıştır. Örneklem grubundan elde verilere açıklayıcı faktör analizi uygulanarak prefabrike yapım sistemlerinin yaygın kullanımına neden olan dokuz faktör belirlenmiştir.

Prefabrike yapım sistemlerinin Türk inşaat sektöründe yaygın kullanılmasını engelleyen faktörler incelendiğinde, sektörde çalışan mimar ile mühendislerin ve ara teknik elemanların bu konuda yeterli bilgi düzeyine sahip olmamalarından kaynaklandığı ifade edilebilir. Bununla birlikte, prefabrike yapım sistemlerinin yapısına uygun yönetim fonksiyonlarının yerine getirilmemesi ve yasal düzenlemelerdeki kısıtlamalar kaynaklı olduğu dikkat çekmektedir.

Türkiye'de prefabrike yapıların daha yaygın bir şekilde kullanılabilmesi için söz konusu süreçlerde görev alan her teknik elemanın çeşitli meslek içi eğitimlerle konuyla ilgili bilgilenmesinin sağlanması; prefabrike yapım sisteminin karakterine uygun organizasyon yapılarının oluşturulması ve özellikle yapı elemanlarının nakliyesi için gerekli yasal düzenlemelerin güncelleştirilmesi önerilmektedir.

Bu çalışmanın prefabrike yapıların tasarım, üretim ve uygulama süreçlerine odaklandığı göz önüne alındığında daha sonra yapılacak çalışmaların prefabrike yapıların kullanım sürecini etkileyen faktörlerin üzerine yoğunlaşması düşünülebilir.

\section{Kaynaklar}

[1] Aydemir, B., Prefabrike Betonarme İskelet Sistemlerle İnşa Edilen Endüstri Yapılarında Prefabrike Döşeme Bileşenlerinin Yük ve Açıklık Kriterleri Açısından İrdelenmesi, Yüksek Lisans Tezi, Dokuz Eylül Üniversitesi, 2005.

[2] Jaillon, L., Poon, C.S., Advantages and Limitations of Precast Concrete Construction in High-Rise Buildings: Hong Kong Case Studies. CIB World Building Congress, Cape Town, 2504-2514, 2007.

[3] Li, Z., Shen, G. Q., Xue, X., Critical Review of The Research on The Management of Prefabricated Construction. Habitat International, 43, 240-249, 2014.

[4] Jaillon, L., Poon, C.S., Design Issues of Using Prefabrication in Hong Kong Building Construction, Construction Management and Economics, 28, 1025-1042, 2010.

[5] Adel, M. B., Heiza, K. M., El-Nawawy, O., Hussein, A., Factors Affecting Over Economy of Prefabricated Construction Systems. International Journal of Advanced Scientific Research and Management, 1(10), 51-63, 2016.

[6] Arditi, D., Ergin, U., Günhan, S., Factors Affecting the Use of Precast Concrete Systems. Journal of Architectural Engineering, (6) 3, 79-86, 2000.

[7] Polat, G., Factors Affecting the Use of Precast Concrete Systems in the United States. Journal of Construction Engineering and Management, 134(3), 169-178, 2008.

[8] Hong, J., Shen, G. Q., Li, Z., Zhang, B., Zhang, W., Barriers to Promoting Prefabricated Construciton in China: A Cost-Benefit Analysis. Journal of Cleaner Production, 172, 649-660, 2018. 
[9] Rausch, C., Nahangi, M., Haas, C., Liang, W., Monte Carlo Simulation for Tolerance Analysis in Prefabrication and Offsite Construction. Automation in Construction, 103, 300-314, 2019.

[10] Li, X., Shen, G. Q., Wu, P., Yue, T., Integrating Building Information Modeling and Prefabrication Housing Production. Automation in Construction, 100, 46-60, 2019.

[11] Wuni, Y. I., Shen, G. Q., Cr,t,cal Success Factors for Management of the Early Stages of Prefabricated Prefinished Volumetric Construction Project Life Cycle. Engineering, Constrution and Architectural Management, 2020.

[12] Sherif, M., Ki, P. K., Vivian, W. Y. T. Payam, R. Exploring the Status, Benefits, Barriers and Opportunities of Using BIM for Advancing Prefabrication Practice. International Journal of Construction Management, 20(2), 146-156, 2020.

[13] Hao, J. L., Cheng, B., Lu, W., Xu, J., Wang, J., Bu, W., Guo, Z., Carbon Emission Reduction in Prefabrication Construction During Materialization Stage: A BIM-Based Life-Cycle Assessment Approach, Science of the Total Environment, 723, $137870, .2020$.

[14] Jiang, W., Huang, Z., Peng, Y., Fang, Y., Cao, Y., Factors Affecting Prefabricated Construction Promotion in China: A Structural Equation Modelling Approach. PLoS ONE, 15(1), e0227787, 2020.

[15] Yuan, Z., Ni, G., Wang, L., Qiao, Y., Sun, C., XU, N., Wang, W., Research on Barrier Analysis and Strength Measurement of a Prefabricated Building Design. Sustainability, 12, 2994, 2020.

[16] Gündüz, L., Kalkan, Ş. O., Lightweight Cellular Hollow Concrete Blocks Containing Volcanic Tuff Powder, Expanded Clay and Diatomite for Non-Load Bearing Walls. Teknik Dergi, 31(6), 2020.

[17] Leskovar, V. Z., Premrov, M., An Approach in Architectural Design of Energy Efficient Timber Buildings With a Focus on the optimal Glazing size in the Southoriented Façade. Energy and Buildings, 43, 3410-3418, 2011.

[18] Şenel, Ş., Palanci, M., Kalkan, A., Yılmaz, Y., Mevcut Prefabrik Binaların Mafsallı Birleşimlerinin Kesme ve Devrilme Güvenliğinin Araştırılması. Teknik Dergi, 24 (119), 6505-28, 2013.

[19] Polat, G., Precast Concrete Systems in Developing vs. Industrialized Countries, Journal of Civil Engineering and Management, 16(1), 85-94, 2010.

[20] Ergen, E., Akinci, B., Formalization of the Flow of Component-Related Information in Precast Concrete Supply Chains. Journal of Construction Engineering and Management, 134, 112-121, 2008.

[21] Pan, W., Gibb, A. G., Dainty, A. R., Strategies for Integrating the Use of Offsite Production Technologies in House Building. Journal of Construction Engineering and Management, 138, 1331-1340, 2012. 
[22] Yin, S. Y., Tserng, H. P., Wang, J., Tsai, S., Developing a Precast Production Management System Using RFID Technology. Automation in Construction, 18, 677$691,2009$.

[23] Gönül, H., Tek Katlı Geniş Açıklıklı Betonarme Prefabrike İskelet Sistemlerle Üretilen Endüstri Yapıları Sorunların Analizi ve Diyarbakır Birinci Organize Sanayi Bölgesi Örneği. Yüksek Lisans Tezi, Gazi Üniversitesi, 2000.

[24] Jaillon, L., Poon, C.S., Life Cycle Design and Prefabrication in Buildings: A Review and Case Studies in Hong Kong. Automation in Construction, 39, 195-202, 2014.

[25] Chan, W.-H., Lu, M., Materials Handling System Simulation in Precast Viaduct Construction: Modeling, Analysis, and Implementation. Journal of Construction Engineering and Management, 134, 300-310, 2008.

[26] Marasini, R., Dawood, N. N., Hobbs, B., Stockyard Layout Planning in Precast Concrete Products Industry: A Case Study and Proposed Framework. Construction Management \& Economics, 19, 365-377, 2001.

[27] Manrique, J. D., Al-Hussein, M., Telyas, A., Funston, G., Constructing a Complex Precast Tilt-Up-Panel Structure Utilizing an Optimization Model, 3D CAD, and Animation. Journal of Construction Engineering and Management, 133, 199-207, 2007.

[28] Marasini, R., Dawood, N., Innovative Managerial Control System (IMCS): An Application in Precast Concrete Building Products Industry. Construction Innovation: Information, Process, Management, 6, 97-120, 2006.

[29] Fang, Y., Ng, S. T., Applying Activity-Based Costing Approach for Construction Logistics Cost Analysis. Construction Innovation: Information, Process, Management, 11, 259-281, 2011.

[30] Vukovic, S., Trivunic, M., Site Management and Production Factors in Concrete Hall Assembly. Building Research \& Information, 22, 272-276, 1994.

[31] Shamsai, M., Whitlatch, E., Sezen, H., Economic Evaluation of Reinforced Concrete Structures with Columns Reinforced with Prefabricated Cage System. Journal of Construction Engineering and Management, 133, 864-870, 2007.

[32] Nunnally, J.C., Bernstein, I.H., Psychometric Theory, New York. McGraw-Hill, 2007.

[33] Büyüköztürk, Ş., Faktör Analizi: Temel Kavramlar ve Ölçek Geliştirmede Kullanımı. Kuram ve Uygulamada Eğitim Yönetimi, 32(32), 470-483, 2002.

[34] George D., Mallery P., SPSS for Windows Step by Step: A Simple Guide and Reference, 11.0 update (4th ed.). Boston. Allyn \& Bacon, 2003. 
